\title{
The Bioassay of Rubratoxins A and B Using Tetrahymena pyriformis Strain $\mathrm{W}$
}

\author{
By T. D. WYATT* AND R. J. TOWNSEND† \\ Department of Food Science and Applied Biology, \\ Polytechnic of the South Bank, Borough Road, London S.E.I
}

(Received I3 April I973; revised I9 July 1973)

\begin{abstract}
SUMMAR Y
Rubratoxin A or B can be assayed by overnight incubation at $25^{\circ} \mathrm{C}$ of a standard inoculum of Tetrahymena pyriformis (Ehrenburg) strain $\mathrm{w}$ in nutrient medium containing differing toxin concentrations. Growth is estimated by measuring the extinction of the organism suspension after inactivation with Hayem's fluid. The values obtained are expressed as a percentage of a normal control. Dose/response curves of percentage inactivation against log concentration of rubratoxin had linear ranges of 2.6 to $23 \mu \mathrm{g} / \mathrm{ml}$ for rubratoxin $\mathrm{A}$ and 8.5 to $30 \mu \mathrm{g} / \mathrm{ml}$ for rubratoxin B. The concentrations of toxin required to produce $50 \%$ inhibition of growth in standard suspensions of $T$. pyriformis strain $\mathrm{w}$ were $8.75 \mu \mathrm{g} / \mathrm{ml}$ and $20 \cdot 5 \mu \mathrm{g} / \mathrm{ml}$ respectively.
\end{abstract}

\section{INTRODUCTION}

Rubratoxins A and B were originally isolated from Pencillium rubrum by Townsend, Moss \& Peck (I966). The chemical structure of rubratoxin A was determined by Moss, Wood \& Robinson (I969) and that of rubratoxin B by Moss, Robinson \& Wood (I968) and Moss, Robinson, Wood, Paisley \& Feeney (I968); both resembled the nonadrides byssochlamic acid, a metabolite of Byssochlamys fulva, and glauconic and glaucanic acids, metabolites of $P$. purpurogenum.

The production of disease symptoms in animals by oral administration of contaminated foodstuffs, toxic fungi or microbial toxins is a well established technique for the bioassay of toxic agents and mycotoxins. Such a method has been used to follow the extraction of rubratoxins from cultures of Penicillium rubrum (Wilson \& Wilson, 1962). The more quantitative dermal patch test seemed to be unsuitable for assaying rubratoxins as New Zealand rabbits were insensitive to extracts of $P$. rubrum (Wilson \& Wilson, 1962). Rubratoxin B produced consistent cytological changes in HeLa cells at concentrations between Io and $32 \mu \mathrm{g} / \mathrm{ml}$ (Natori et al. 1970) although no attempt at quantification was made.

The growth of several micro-organisms can be inhibited by rubratoxins. Bacillus subtilis, B. cereus, Staphylococcus aureus (Wilson \& Wilson, 1962) and Chlorella pyrenoidosa (Ikawa, Ma, Meeker \& Davis, I969) were inhibited by crude rubratoxins and Hayes \& Wyatt (1970) demonstrated inhibition of growth of Volvox aureus and Tetrahymena pyriformis (undefined strain) at concentrations of less than $50 \mu \mathrm{g} / \mathrm{ml}$ of pure rubratoxin B.

Tetrahymena pyriformis strain $\mathrm{w}$ has been widely used in the assessment of the nutritional

* Present address: Department of Microbiology, The Queen's University of Belfast, Grosvenor Road, Belfast, BT I 2 6BN, Northern Ireland.

$\dagger$ Present address: Department of Natural Sciences, Norwood Technical College, Knight's Hill, London, S.E. 27. 
value of proteins with results comparable to those obtained using rats (Rosen, I960; Celliers, I96r; Teunisson, I96I; Stott \& Smith, 1966). This communication reports an investigation into the usefulness of the inhibition of multiplication of $T$. pyriformis strain $\mathrm{W}$ as a bioassay system for both rubratoxin $\mathrm{A}$ and $\mathrm{B}$.

\section{METHODS}

Organism. Tetrahymena pyriformis (Ehrenburg) strain w was obtained from the Culture Collection of Algae and Protozoa, 36 Storey's Way, Cambridge.

Stock cultures were maintained at $25{ }^{\circ} \mathrm{C}$ in $\mathrm{ro} \mathrm{ml}$ of nutrient medium ( $\%$, w/v, Bacteriological Peptone and $0.25 \%$, w/v, yeast extract, Oxoid Ltd, Southwark Bridge Road, London S.E.I) in loosely capped Universal bottles. Subculture was carried out weekly by transferring $0.2 \mathrm{ml}$ of actively growing culture to $\mathrm{IO} \mathrm{ml}$ of fresh nutrient medium.

A standard suspension of organisms was prepared as follows: $0.4 \mathrm{ml}$ of an exponential phase culture of organisms was transferred to $150 \mathrm{ml}$ of sterile nutrient medium in a $\mathrm{I} 200 \mathrm{ml}$ low form culture flask. After incubation at $25{ }^{\circ} \mathrm{C}$ for $24 \mathrm{~h}$, the suspension was diluted with nutrient medium to an extinction between 0.04 and 0.06 (see Measurement of growth).

Toxin solution. Samples of pure and impure rubratoxin A and B were kindly provided by Dr M. O. Moss of the Tropical Products Institute, 56-62 Grays Inn Road, London W.C. I. Stock solutions in sodium bicarbonate solution (0.0 $2 \mathrm{M}$ ), $\mathrm{pH} 9 \cdot 6$, were sterilized by membrane filtration (pore size $220 \mathrm{~nm}$ ) and diluted with bicarbonate to give twenty times the final concentration required in the assay tube.

Preparation of assay. Three replicate tubes were prepared for each rubratoxin concentration, controls and reagent blanks by adding the following components to sterile, dry, rimless boiling tubes with aluminium caps: $8.5 \mathrm{ml}$ of sterile nutrient medium, $0.5 \mathrm{ml}$ of toxin dilution or sodium bicarbonate diluent and $\mathrm{x} \cdot 0 \mathrm{ml}$ of standard organism suspension or $1.0 \mathrm{ml}$ of nutrient medium in reagent blanks. Medium for each complete assay was taken from the same batch. During inoculation, the suspension of organisms was stirred in a $250 \mathrm{ml}$ conical flask with four projections in the bottom to ensure the homogeniety of samples.

After mixing, the assay tubes were randomly arranged and incubated at $25^{\circ} \mathrm{C}$ for $24 \mathrm{~h}$ in racks inclined at approximately $5^{\circ}$.

Measurement of growth. After incubation, assay tubes were placed at $15{ }^{\circ} \mathrm{C}$. The tubes were then assessed from the highest to the lowest toxin concentration in each replicate using a Hitachi Perkin Elmer Model I 24 double beam spectrophotometer at a wavelength of $550 \mathrm{~nm}$ with cells of $\mathrm{I} \mathrm{cm}$ path length.

Between 0.2 and $0.4 \mathrm{ml}$ of Hayem's fluid $(0.25 \%, \mathrm{w} / \mathrm{v}$, mercuric chloride, $0.5 \%$, w/v, sodium chloride, and $0.25 \%$, w/v, sodium sulphate), depending on the concentration of organisms, was added to the cellular suspension. Extinctions for each tube were read between 25 and $35 \mathrm{~s}, 85$ and $95 \mathrm{~s}$, and I 45 and I 55 s after adding Hayem's fluid. The sample was returned to the boiling tube and shaken between each reading; $30 \mathrm{~s}$ was allowed before reading to decrease turbulence in the cell. Measurements were recorded on a Perkin Elmer Model I 65 chart recorder. None of the compounds added to the culture medium absorbed at the wavelength used for assessment. The mean extinction per replicate was calculated from the three observations thus obtained and the mean extinction per toxin concentration was expressed as a percentage of the control. This gave a measure of the percentage inhibition of growth.

The statistical variation of extinction values between tubes in the same assay was determined using $0.5 \mathrm{ml}$ of sterile sodium bicarbonate solution (0.01 $2 \mathrm{M})$ instead of a toxin 
dilution. Tubes were incubated for different lengths of time to provide a range of extinctions. For each level of mean extinction, 'significance levels' were calculated from the formula :

$$
\text { Significance level }=2 \times \sqrt{2} \times \text { S.D. } / \sqrt{ } 3
$$

in which 2 is taken as the approximate value of Student's $t$ at the $95 \%$ significance level with the appropriate number of degrees of freedom, $\sqrt{ } 2$ refers to the number of samples being compared (2), and S.D./ $/ 3$ is an estimate of the standard deviation of the mean extinction obtained from 3 replicates.

The line of best fit, the gradients and the $95 \%$ confidence limits of inactivation curves for impure samples of both rubratoxins were calculated according to Brownlee (1953).

Observations on procedure. The extinction of assay tubes was measured after $24 \mathrm{~h}$ incubation at $25^{\circ} \mathrm{C}$ as preliminary observations had shown that the organisms in control cultures were in the mid-exponential phase of growth at this time. An additional buffering system was not included in the assay tubes as no significant $\mathrm{pH}$ change was detectable in control tubes or tubes containing up to $100 / \mathrm{g} / \mathrm{ml}$ of either rubratoxin after the incubation period.

When reading the extinction of live suspensions of Tetrahymena pyriformis strain $\mathrm{w}$, non-uniform changes in the extinction were observed because of the motility of the organisms. Of the potential inactivators assessed, Hayem's fluid was the most effective, allowing reproducible extinction measurements to be made as no cell deformation or lysis was observed during the period of assessment.

\section{RESULTS}

The effect of the rubratoxins on the growth of T. pyriformis strain $\mathrm{W}$

Cultures of Tetrahymena pyriformis strain $\mathrm{W}$ were incubated with concentrations of pure rubratoxins A and B between 0.05 and $150 \mu \mathrm{g} / \mathrm{ml}$. The results (Fig. I) suggested linear ranges of inhibition from 2.6 to $25 \mu \mathrm{g} / \mathrm{ml}$ for rubratoxin $\mathrm{A}$, and from 8.5 to $30 \mu \mathrm{g} / \mathrm{ml}$ for rubratoxin $\mathrm{B}$, with $\mathrm{ED}_{50}$ values (effective dose 50: the concentration of rubratoxin required to produce $50 \%$ growth inhibition) of 8.75 and $20.5 \mu \mathrm{g} / \mathrm{ml}$ respectively. Also included in Fig. I are typical dose/response curves for impure samples of rubratoxin $\mathrm{A}$ and $\mathrm{B}$.

As shown by a comparison of the $\mathrm{ED}_{50}$ values in Fig. I, impure samples of rubratoxin $\mathrm{A}$ and $\mathrm{B}$ appeared more toxic than pure samples; by visual inspection, the gradients of inactivation curves for pure and impure toxin samples also differed.

Variation in extinction between tubes in the same assay are shown in Table $\mathrm{I}$. The standard deviation obtained, whilst generally low, increased with extinction. By plotting the 'significance levels' derived from these results against the corresponding extinction (Fig. 2) it was possible to determine whether average extinctions for particular toxin concentrations were significantly different from those obtained for other toxin concentrations. Thus, in the region of extinction 0.2 (Fig. 2), variations greater than 0.0 I I were significantly different.

The statistical validity of the assay system was ascertained using four impure samples of rubratoxin $\mathrm{A}$ and two of impure rubratoxin B. The parameters of the line of best fit and the correlation coefficients of these dose/response curves (Table 2) indicated that the formula of the line was $y=a+b x$. Probit analysis of the degree of inactivation extended the linear portion of the lines and confirmed that the dose/response curves were linear over the dose range previously mentioned.

A comparison of the four gradients obtained for impure rubratoxin A showed that they were not significantly different $\left(F=2.9134 ; n_{1}=3 ; n_{2}=21 ; 0.01>P>0.05\right)$ in spite 


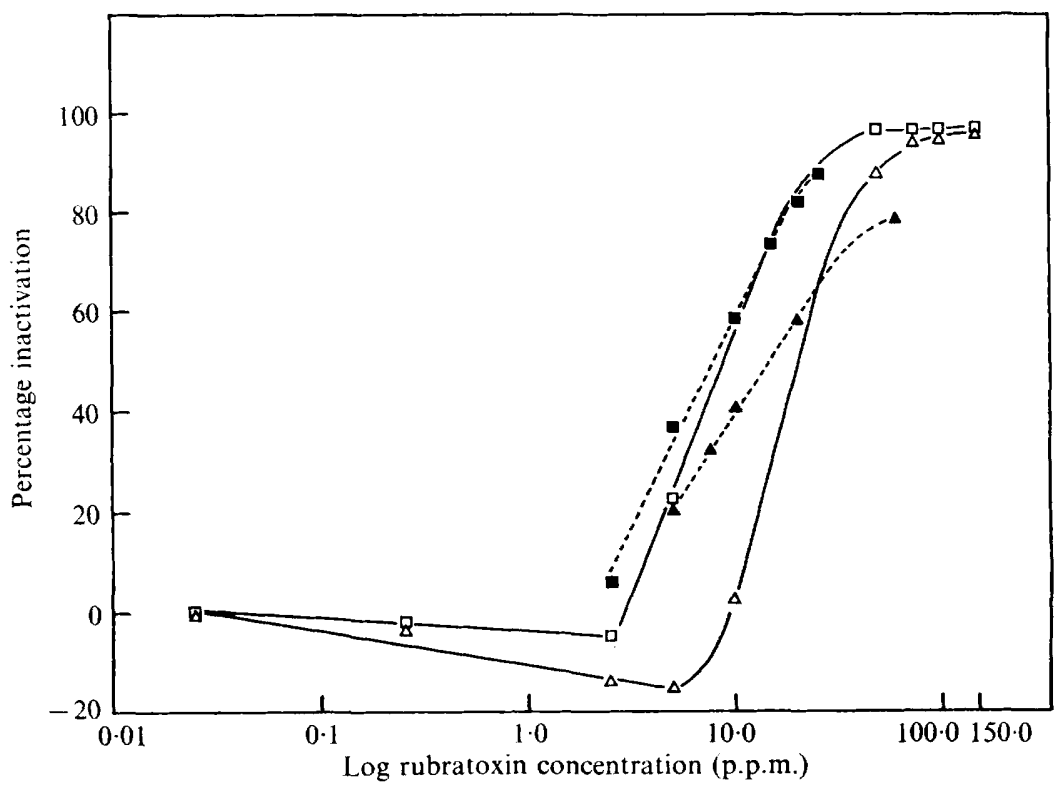

Fig. I. Dose/response curves of pure and impure rubratoxins A and B.

$\begin{array}{lccc}\text { Rubratoxin } & \text { Symbol } & \begin{array}{c}\mathrm{ED}_{50} \\ \text { (p.p.m.) }\end{array} & \text { Gradient } \\ \text { A (pure) } & & 8 \cdot 9 & 2 \cdot 5 \\ \text { A (impure) } & - & 7 \cdot 8 & 2 \cdot 0 \\ \text { B (pure) } & & 20 \cdot 5 & 3 \cdot 2 \\ \text { B (impure) } & - & 14 \cdot 0 & 1 \cdot 5\end{array}$

Table I. Statistical variation occurring within the assay procedure

Assays used $0.5 \mathrm{ml}$ of sterile sodium bicarbonate solution $(0.012 \mathrm{M})$ rather than a toxin dilution, and differing incubation times were chosen to vary the mean extinction.

$\begin{array}{ccccc}\begin{array}{c}\text { Assay } \\ \text { no. }\end{array} & \begin{array}{c}\text { Mean } \\ \text { extinction } \\ E_{550}\end{array} & \begin{array}{c}\text { No. of } \\ \text { tubes }\end{array} & \begin{array}{c}\text { Standard } \\ \text { deviation }\end{array} & \begin{array}{c}\text { 'Significance } \\ \text { levels' }\end{array} \\ \text { I } & 0.604 & 17 & 0.0189 & 0.0309 \\ 2 & 0.461 & 20 & 0.0122 & 0.0199 \\ 3 & 0.446 & 16 & 0.0130 & 0.0211 \\ 4 & 0.303 & 18 & 0.0089 & 0.0145 \\ 5 & 0.195 & 17 & 0.0085 & 0.0139 \\ 6 & 0.045 & 17 & 0.0023 & 0.0038\end{array}$

of assays $A_{3}$ and $A_{4}$ having lower gradients than assays $A_{1}$ and $A_{2}$. Similarly, gradients obtained in two assays of impure rubratoxin $B$ did not differ significantly from each other $\left(F=0.6 \mathrm{I} 90 ; n_{1}=\mathrm{I} ; n_{2}=7 ; P>0.2\right)$.

The $\mathrm{ED}_{50}$ values obtained in the above assays were adjusted to the common slopes (rubratoxin A, $2 \cdot 3287$; rubratoxin $\mathrm{B}, \mathrm{I} \cdot 7285$ ) as shown in Table 3 . The logs of the adjusted $E_{50}$ values were then compared using the method of Finney (I962). No significant difference was obtained for impure rubratoxin A (Table 4) and the difference obtained for the two assays of impure rubratoxin B (Table 3) was $-0.0564 \pm 0.4158$ and was thus not significantly different from zero. 


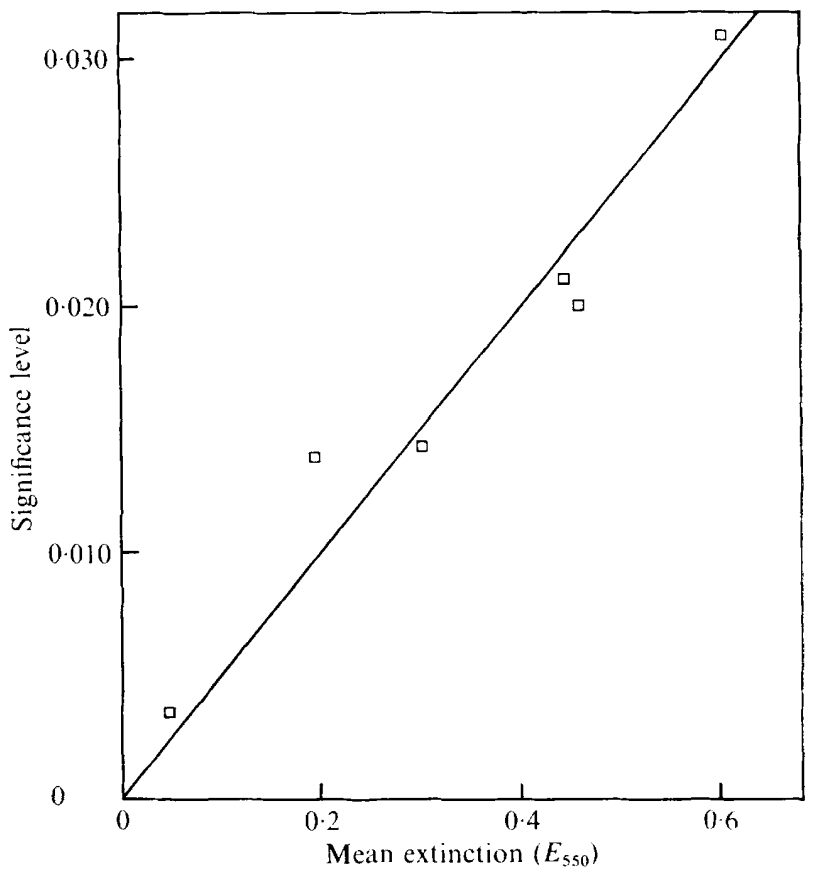

Fig. 2. The relationship between 'significance levels' and extinction. Data were obtained from Table I. For example, in the region of $E 0^{\cdot 2}$, only differences of at least 0.011 were significant.

Table 2. Statistical parameters from dose/response curves of impure rubratoxin $A$ and $B$

Probit analysis of the degree of inactivation, rather than percentage inactivation (Fig. 1), was used for these curves. The formula of the lines obtained was $y=a+b x$.

No. of

Rubratoxin points on assay no. line

$A_{1}$
$A_{2}$
$A_{3}$
$A_{4}$
$B_{1}$
$B_{2}$

10

9

6

4

6

5

$a$
$2 \cdot 7540$
$2 \cdot 6985$
$3 \cdot 2914$
$3 \cdot 3380$
$3 \cdot 2329$
$3 \cdot 0181$

b

$2 \cdot 4635$

$2 \cdot 4397$

2. 1025

I. 9049

I. 6608

I. 7460

\section{Correlation} coefficient

0.985
0.997
0.993
0.998
0.992
0.998

Table 3. Comparison of $E D_{50}$ 's obtained from assays of impure rubratoxins $A$ and $B$

The data were obtained from assays presented in Table 2. Adjusted ED 50 s were based on the common slopes obtained for rubratoxins A and B (2.3287 and 1.7285 respectively). Figures in parentheses are the standard errors of the $\log \mathrm{ED}_{50}$ 's.

\begin{tabular}{|c|c|c|c|c|}
\hline \multirow{2}{*}{$\begin{array}{c}\text { Rubratoxin } \\
\text { assay } \\
\text { number }\end{array}$} & \multicolumn{2}{|l|}{$E D_{50}$} & \multicolumn{2}{|c|}{ Adjusted $E D_{50}$} \\
\hline & $\log$ & $\begin{array}{c}\text { Dose } \\
\text { (p.p.m.) }\end{array}$ & $\log$ & $\begin{array}{c}\text { Dose } \\
\text { (p.p.m.) }\end{array}$ \\
\hline$A_{1}$ & $0.9085( \pm 0.1424)$ & $8 \cdot I$ & $0.9035( \pm 0.1420)$ & $8 \cdot 008$ \\
\hline$A_{2}$ & $0.9494( \pm 0.1460)$ & $8 \cdot 9$ & $0.9362( \pm 0.1495)$ & $8 \cdot 634$ \\
\hline$A_{3}$ & $0.8129( \pm 0.3215)$ & $6 \cdot 5$ & $0.8512( \pm 0.2011)$ & 7.099 \\
\hline $\mathbf{A}_{4}$ & $0.8865( \pm 0.3199)$ & $7 \cdot 7$ & $0.9037( \pm 0.2182)$ & $8 \cdot 0$ I I \\
\hline $\mathbf{B}_{1}$ & $1.0607( \pm 0.5873)$ & $11 \cdot 5$ & $1.0788( \pm 0.3236)$ & II $\cdot 990$ \\
\hline $\mathrm{B}_{2}$ & $I \cdot I 46 I( \pm 0.2563)$ & 14.0 & $I \cdot 135 I( \pm 0.2587)$ & 13.650 \\
\hline
\end{tabular}


Table 4. Comparison of the adjusted log $E D_{50}$ 's obtained for the four assays of impure rubratoxin $A$

The adjusted $\log E D_{50}$ 's were obtained from Table 3 and the standard errors calculated as described by Finney ( 1962 ).

$\begin{array}{cccc} & A_{2} & A_{3} & A_{4} \\ A_{1} & -0.0327 \pm 0.1968 & 0.0523 \pm 0.1532 & 0.0002 \pm 0.1629 \\ A_{2} & - & 0.0851 \pm 0.2327 & 0.0325 \pm 0.2578 \\ A_{3} & - & - & 0.0526 \pm 0.2786\end{array}$

\section{DISCUSSION}

This study has confirmed the toxicity of rubratoxin B to Tetrahymena pyriformis found by Hayes \& Wyatt (I970). The method adopted in the present study was more sensitive and gave a minimum inhibitory concentration of $8.5 \mu \mathrm{g} / \mathrm{ml}$ (Fig. 1) for the pure material compared with $25 \mu \mathrm{g} / \mathrm{ml}$ reported previously.

The statistical variations in the assay procedure were determined using impure samples of rubratoxins $\mathrm{A}$ and $\mathrm{B}$. The greater standard deviation at high extinctions (Table I) probably resulted from light scattering and reflection during assessment. The correlation coefficients (Table 2) varied between 0.985 and 0.998 , indicating that the dose/response curves could be represented by a single straight line of formula $y=a+b x$. The common slope of the four lines obtained in assays of impure rubratoxin A and the two lines obtained for impure rubratoxin $B$ were used to compare the $E_{50}$ values (Tables 3 and 4 ). No significant difference was evident between the $\mathrm{ED}_{50}$ values obtained for impure rubratoxin A (Table 4) or impure rubratoxin B (see above). As these samples of toxins were impure, a comparison of their $\mathrm{ED}_{50}$ values would be of little use. However, the results indicated that the bioassay system gave reproducible gradients and $E_{50}$ 's. Although variations within and between tests were generally small when using the described assay procedure, a reduction in the number of replicates from three to two or one lowered the accuracy of the method. When less precision was required, a reduction in the number of replicates was satisfactory.

No statistical data can be presented for the assays of pure rubratoxin A and B; probably such assays will have similar variations to those using impure material.

Visual comparison of the $\mathrm{ED}_{50}$ 's in Fig. I suggested that impure samples of both rubratoxins were more toxic than pure samples and the gradients of the dose/response curves for pure and impure samples seemed to be different, although the statistical significance of these differences could not be assessed. This suggested the presence of a biologically active contaminant in the impure material. As a later preparation of rubratoxin B obtained from Penicillium rubrum MR 80 , a strain known to produce only rubratoxin B (Moss \& Hill, 1970), gave dose/response parameters of the same gradient as pure rubratoxin $B$, crosscontamination of rubratoxins $A$ and $B$ probably occurred in the impure samples.

Although the statistical difference in $\mathrm{ED}_{50}$ between pure and impure samples of rubratoxin A and B could not be assessed, it seems likely that pure samples of these toxins could be differentiated on the basis of their toxicity to Tetrahymena pyriformis strain $\mathrm{w}$.

A characteristic feature of the dose/response curves for both rubratoxins was the region of growth stimulation at subinhibitory toxin levels (Fig. 1). This stimulation was significantly different from control values at $2.5 \mu \mathrm{g} / \mathrm{ml}$ for rubratoxin $A$ and 2.5 and $5.0 \mu \mathrm{g} / \mathrm{ml}$ for rubratoxin B, using significance levels calculated as described (Table 1 , Fig. 2). This method 
was not precise, as the linear relationship between significance levels and mean extinction in Fig. 2 was tenuous although approximate values could be obtained. Apparent growth stimulation has often been observed in antibiotic assays and is thought to result from the relationship between cell size and population density of the assay organism (Kavanagh, 1963). Since Tetrahymena pyriformis organisms are at maximum size in the late exponential and early stationary phase of growth (Allison \& Ronkin, 1967) and organisms recovering from the effects of inhibitors tend to divide more rapidly than control organisms (Rasmussen, I967), this apparent stimulatory effect was probably an artifact.

Using this assay system for the measurement of rubratoxins present in contaminated foodstuffs, it is likely that the response of Tetrahymena pyriformis strain $w$ would be modified by nutrients and inhibitors from the foodstuffs. Also the particulate nature of the foodstuffs would cause difficulties in the measurement of the extinction of suspensions. Toxin sufficiently pure for assay could probably be extracted from the contaminated foodstuff with ether (Hayes \& Wilson, 1968) although the effect on the dose/response curve of contaminating compounds still present in the crude toxin would need to be investigated.

The assay system described has the advantage over animal systems of being quantitative, rapid and repeatable. An assay for rubratoxin B employing thin-layer chromatography described by Moss \& Hill (1970) and by Hayes, Wyatt \& King (1970) was not used quantitatively, possibly because of lack of sensitivity or the occurrence of artifacts. Moss \& Hill ( 1970 ) devised a quantitative assay for rubratoxin A (between 0 and $\mathrm{I} \cdot 0 \mathrm{mg} / \mathrm{ml}$ ) based on its formation of heptaldehyde when dissolved in sodium hydroxide. However, rubratoxin $B$ reacted only slightly under these conditions.

Tetrahymena pyriformis strain $\mathrm{w}$ therefore provides a useful means of bioassaying both rubratoxin A and B. However, as with all bioassay systems, the influence of contaminating compounds on the dosage response curve when assaying impure compounds requires thorough investigation.

We are grateful to Mr D. D. Filtness and Dr D. J. Merrett for assistance with the statistics. Some of the work reported here was included in a Ph.D. thesis submitted by T.D.W. to the University of Bradford in June, 1972.

\section{REFERENCES}

Allison, B. M. \& Ronkin, R. R. (1967). Lipid cytochemistry and morphologic change in ageing populations of Tetrahymena. Journal of Protozoology r4, 313-3I9.

Brownlee, K. A. (1953). Industrial Experimentation. London: H.M.S.O. Chemical Publishing.

Celliers, P. G. (I96I). Microbiological evaluation of the nutritive value of South African marine products with Tetrahymena pyriformis w. South African Journal of Agricultural Science 4, 191-204.

Finney, D. J. (1962). Probit Analysis, 2nd edn. Cambridge: University Press.

Hayes, A. W. \& Wilson, B. J. (1968). Bioproduction and purification of rubratoxin B. Applied Microbiology I6, II $63-1167$.

Hayes, A. W. \& WyAtT, E. P. (I970). Survey of the sensitivity of micro-organisms to rubratoxin B. Applied Microbiology 20, 164-165.

Hayes, A. W., WyatT, E. P. \& KInG, P. A. (1970). Environmental and nutritional factors affecting the production of rubratoxin B by Penicillium rubrum Stoll. Applied Microbiology 20, 469-473.

IkaWA, M., MA, D. S., Meeker, G. B. \& Davis, R. P. (1969). Use of Chlorella in mycotoxin and phycotoxin research. Journal of Agricultural and Food Chemistry $\mathbf{1 7}, 425-429$.

Kavanagh, F. (1963). Analyical Microbiology. London and New York: Academic Press.

Moss, M. O. \& Hill, I. W. (1970). Strain variation in the production of rubratoxin by Pencillium rubrum Stoll. Mycopathologia et mycologia applicata 40, 8I-88. 
Moss, M. O., Robinson, F. V. \& Wood, A. B. (1968). Rubratoxin B, a toxic metabolite of Penicillium rubrum. Chemistry and Industry, 587-589.

Moss, M. O., Robinson, F. V., Wood, A. B., Paisley, H. M. \& Feeney, J. (1968). Rubratoxin B, a proposed structure for a bis-anhydride from Penicillium rubrum Stoll. Nature, London 220, 767-770.

Moss, M. O., Wood, A. B. \& Robinson, F. V. (1969). The structure of rubratoxin A, a toxic metabolite of Penicillium rubrum. Tetrahedron Letters 5, 367-370.

Natori, S., Sakaki, S., Kurata, H., Udagawa, S., Ichinoe, M., Saito, M., Umeda, M. \& Ohtsubo, K. (1970). Production of rubratoxin B by Penicillium purpurogenum Stoll. Applied Microbiology 19, 6I $3-617$.

Rasmussen, L. (1967). Effects of metabolic inhibitors on Paramecium aurelia during the cell generation cycle. Experimental Cell Research 48, I $32-139$.

Rosen, G. D. (1960). The micro-biological assay of protein quality. In Proceedings of International Symposium on Micro-chemistry, pp. 212-219. Edited by D. Wilson. London: Pergamon Press.

Stoтt, J. A. \& Sмгтн, H. (1966). Microbiological assay of protein quality with Tetrahymena pyriformis w. British Journal of Nutrition 20, 663-673.

Teunisson, D. J. (I96I). Microbiological assay of intact proteins using Tetrahymena pyriformis w. I. Survey of protein concentrates. Analytical Biochemistry 2, 405-420.

Townsend, R. J., Moss, M. O. \& PeCk, H. M. (I966). Isolation and characterisation of hepatotoxins from Penicillium rubrum. Journal of Pharmacy and Pharmacology 18, 47 I-473.

Wilson, B. J. \& WiLson, C. H. (1962). Extraction and preliminary characterisation of a hepatotoxic substance from cultures of Penicillium rubrum. Journal of Bacteriology 84, 283-290. 